\title{
ПЕДАГОГІЧНІ УМОВИ АКТИВІЗАЦІЇ НАВЧАЛЬНОЇ ДІЯЛЬНОСТІ МАЙБУТНІХ ІНЖЕНЕРІВ-ПЕДАГОГІВ КОМП'ЮТЕРНОГО ПРОФІЛЮ
}

and the artistic culture of the listener.]. Kyiv: Muzika Publ., 192 p. [in Ukrainian].

7. Pavlenko, I. H. (2002). Formuvannia ekolohichnoi kultury molodshykh shkoliariv zasobamy mystetstva [Developing primary schoolchildren's ecological culture by means of art]. Extended abstract of candidate's thesis. Lugansk, 20 p. [in Ukrainian].

8. Rozdymakha, A. I. (2017). Vyvchennia problemy formuvannia zdatnosti do estetychnoi otsinky yavyshch diisnosti zasobamy mystetstva [Studying the problems of forming the capacity to estimate phenomenon of reality by means of art].
Professionalism of the teacher: theoretical and methodical aspects. Slavyansk: DDPU Publ., vol. 5, part.1, pp. 213-225. [in Ukrainian].

9. Popova, L. D. \& Ureva, K. A. (1993). Sukhomlynskyi V. O.: Pro estetychnu kulturu vchytelia [Sukhomlynskyi V. O.: About the aesthetic culture of the teacher]. Guidelines. Kharkiv: HDPI Publ., 324 p. [in Ukrainian].

10. Fed, A. M. (2001). Notatky na poliakh nenapysanoho etiudu. Kinopovist ta dva esei. [Notes on the fields of unwritten sketch. The film and two essays.]. Slavyansk: DDPU Publ.,pp. 122-132. [in Ukrainian].

УДК 378.147

DOI:

Ольга Єсіпова, асистент кафедри педагогіки методики та менеджменту освіти Української інженерно-педагогічної академії, м. Харків

\section{ПЕДАГОГІЧНІ УМОВИ АКТИВІЗАЦІЇ НАВЧАЛЬНОЇ ДІЯЛЬНОСТІ МАЙБУТНІХ ІНЖЕНЕРІВ-ПЕДАГОГІВ КОМП'ЮТЕРНОГО ПРОФІЛЮ}

У статті розглянуто поняття “педагогічні умови”. На основі логічного аналізу, враховуючи теоретичні напрацювання науковців та педагогічний досвід визначено педагогічні умови активізації навчальної діяльності майбутніх інженерів-педагогів комп ютерного профілю, до яких відноситься зміна позиції студента в навчальній діяльності иляхом проектного підходу до ї̈ організації; мотивації в прочесі навчання иляхом інтеграції інформаційно-комунікаційних технологій в процесі навчання педагогічних дисциилін;корекція навчальної діяльності в прочесі оперативного зворотного зв 'язку.

Ключові слова: умова; педагогічні умови; активізачія навчальної діяльності; зміна позиції студента; мотивація; оперативний зворотній зв'язок.

Jim. 9.

Olha Yesipova, Assistant of the Pedagogy, Methodology and Management of Education Department Ukrainian Engineering Pedagogical Academy, Kharkiv

\section{PEDAGOGICAL CONDITIONS OF ACTIVATION OFTHE TRAINING ACTIVITY OF THE FUTURE ENGINEERS OF THE COMPUTER PROFILE}

The article deals with the concepts "conditions", "pedagogical conditions". As a result of a comprehensive analysis of the concept "conditions", one can conclude that it is a general scientific one, and its essence in the pedagogical aspect can be characterized by several provisions: the condition is the set of causes, circumstances, any objects, etc.; the designated population affects the development, education and training of a person; the impact of conditions can accelerate or slow down the processes of development, education and training, and also affect their dynamics and outcomes. The definition of the essence of the concept "pedagogical conditions" involved a number of scientists. However, there is no single definition in their interpretations. On the basis of analysis, only some of them, which are usually based on the researchers, found that in pedagogical conditions we mean a set of objective possibilities, content, forms, methods and material-spatial environment aimed at solving educational problems. On the basis of logical analysis, taking into account the theoretical developments of scientists and pedagogical experience, pedagogical conditions are formed for activating the educational activity of future computer engineers, which include the changing of the position of the student in the training activity through the project approach to organization; motivation of the learning process by integrating the information and communication technologies into the teaching of pedagogical disciplines; correction of educational activity in the process of prompt feedback.

Keywords: a state; pedagogical conditions; an activation of educational activity; changing of student position; a motivation; operational feedback.

П остановка проблеми. Сьогодні Україна зробила свідомий вибір на користь загальноєвропейської інтеграції. Входження нашої країни в цивілізоване світове співтовариство висуває нові вимоги до організації навчального процесу, навчальної 


\section{ПЕДАГОГІЧНІ УМОВИ АКТИВІЗАЦІЇ НАВЧАЛЬНОЇ ДІЯЛЬНОСТІ МАЙБУТНІХ ІНЖЕНЕРІВ-ПЕДАГОГІВ КОМП'ЮТЕРНОГО ПРОФІЛЮ}

діяльностіта взагаліпідготовки висококваліфікованого фахівця. Перед вищою школою постає завдання створити такі умови організації навчального процесу та навчальної діяльності, щоб майбутній фахівець, в тому числі й інженер-педагог комп’ютерного профілю в результаті навчання зміг реалізувати наступні якості: мобільність, гнучкість, здатність до самоосвіти та саморозвитку, швидко орієнтуватися в сучасному насиченому інформаційному просторі, творчо мислити, висування та приймання нестандартних рішення, генерувати оригінальних ідеї, вчитися і розвиватися протягом усього життя.

Підготовка такого фахівця можлива лише за умови проявлення активності майбутніх інженерів-педагогів комп'ютерного профілю під час засвоєння професійних знань та умінь в процесі навчальної діяльності у вищому навчальному закладі.

Аналіз останніх досліджень і публікацій. Навчальна діяльність неодноразово була об' єктом системних досліджень психологів Б. Ананьєва, Л. Виготського, О. Леонтьєва, С. Рубінштейна та педагогів Л. Арістова, В. Сластьоніна, I. Харламова, Т. Шамової та інших. Поняття “педагогічні умови” розглядали в своїх наукових працях, низка вітчизняних та зарубіжних вчених, серед них В. Андреєв, Ю. Бабанський, О. Бережнова, К. Біктагірова, С. Диніна, М. Звєрєва, Б. Купріянов, В. Манько, А. Найн, І. Підласий, О. Федорова, Є. Яковлєв та інші.

Мета статті виявити та охарактеризувати педагогічні умови активізації навчальної діяльності майбутніх інженерів-педагогів комп'ютерного профілю.

Виклад основного матеріалу. У тлумачному словнику української мови зазначається, що умова - це "необхідна обставина, яка робить можливим здійснення, створення, утворення чого-небудь або сприяє чомусь” [7]. Філософське та, відповідно, загальнонаукове тлумачення поняття "умова" зводиться до істотного компонента комплексу об'єктів (речей, їх станів, взаємодій), за наявності якого з необхідністю слідує існування певного явища (об'єкта). Умова - це те, від чого залежить дещо інше; те,що робить можливим наявність предмета, стану, процесу [9]. Інакше кажучи, умови - це стабільні обставини, які оточують об'єкт і визначають природу впливу на нього, імплікаційний зв'язок.

Педагоги розглядають умову як сукупність змінних природних, соціальних, зовнішніх і внутрішніх впливів, що впливають на фізичне, моральне, психічне розвиток людини, його поведінка, виховання і навчання, формування особистості (В.М. Полонський). Таким чином, результати комплексного аналізу дозволяють зробити висновок, що поняття “умова" $\epsilon$ загальнонауковим, а його сутність в педагогічному аспекті може бути охарактеризована кількома положеннями:

1. Умова $є$ сукупність причин,обставин, будьяких об'єктів і т.д .;

2. Позначена сукупність впливає на розвиток, виховання і навчання людини;

3. Вплив умов може прискорювати або уповільнювати процеси розвитку, виховання і навчання, а також впливати на їх динаміку і кінцеві результати.

У сучасних дослідженнях поняття “умова" використовується досить широко при характеристиці педагогічної системи. При цьому вчені, спираючись на різні ознаки, виділяють різні групи умов. Так, Ю.К. Бабанський по сфері впливу виділяє дві групи умов функціонування педагогічної системи: зовнішні (природногеографічні, суспільні, виробничі,культурні, середовища мікрорайону) і внутрішні (навчальноматеріальні, морально-психологічні естетичні) [2].

За характером впливу виділяють об'єктивні і суб'єктивні умови. Об'єктивні умови, що забезпечують функціонування педагогічної системи, включають нормативно-правову базу сфери освіти, засоби інформації тощо, і виступають в якості однієї з причин, спонукають учасників освіти до адекватних проявів себе в ній.

За специфікою об'єкта впливу виділяють загальні та специфічні умови, сприяють функціонуванню та розвитку педагогічної системи. До загальних умов відносяться соціальні, економічні, культурні, національні, географічні та інші умови; до специфічних - особливості соціально-демографічного складу навчального колективу; місце знаходження освітнього закладу; матеріальні можливості освітньої установи, обладнання навчально-виховного процесу; тощо [5].

Визначенням сутності поняття “педагогічні умови” займалася низка вчених. Однак одностайності уїх визначеннях не простежується. Проаналізуємо лише деякі з них, на які, зазвичай, спираються дослідники. На думку О. Федорова під педагогічними умовами розуміє сукупність об'єктивних можливостей змісту навчання, методів, організаційних форм і матеріальних можливостей іiі здійснення, які забезпечують успішне вирішення поставленого завдання. К. Біктагірова говорить, що педагогічні умови обставини, при яких компоненти навчального процесу (зміст, викладання й учіння) подані в 


\section{ПЕДАГОГІЧНІ УМОВИ АКТИВІЗАЦІЇ НАВЧАЛЬНОЇ ДІЯЛЬНОСТІ МАЙБУТНІХ ІНЖЕНЕРІВ-ПЕДАГОГІВ КОМП'ЮТЕРНОГО ПРОФІЛЮ}

найкращому взаємозв'язку та створюють атмосферу плідної співпраці, що забезпечує продуктивне викладання, управління навчальним процесом, а також успішне навчання. За М. Звєрєвою, це змістова характеристика одного 3 компонентів педагогічної системи, в якості якого виступають зміст, організаційні форми, засоби навчання і характер взаємин між учителем та учнями. Ю. Бабанський визначає педагогічні умови як чинники (обставини), від яких залежить ефективність функціонування педагогічної системи.

Приєднуємося до науковців, які розуміють під педагогічними умовами сукупність об'єктивних можливостей, змісту, форм, методів і матеріальнопросторового середовища, спрямованих на вирішення поставлених освітніх завдань.

Таким чином на основі логічного аналізу, враховуючи теоретичні напрацювання науковців та педагогічний досвід нами було визначені наступні педагогічні умови активізації навчальної діяльності майбутніх інженерів-педагогів комп'ютерного профілю:

- зміна позиції студента в навчальній діяльності шляхом проектного підходу до її організації;

- зміна мотивації в процесі навчання шляхом інтеграції інформаційно-комунікаційних технологій в процесі навчання педагогічних дисциплін;

- корекція навчальної діяльності в процесі оперативного зворотного зв'язку.

Охарактеризуємо першу умову - зміна позиції студента в навчальній діяльності шляхом проектного підходу до ї̈ організації. Ю.К.Бабанський виділяє як ланку процесу навчання дидактичну взаємодію педагога i студентів [1]. Вона $€$ центральною в структурі процесу навчання. Виокремлення цієї ланки $є$ досить умовним, оскільки взаємодія педагогів і студентів пронизує увесь процес навчання в цілому. Дидактичну взаємодію викладача i студентів розглядають як взаємозв'язок особистостей в процесі навчання, що реалізується через спільні дії і характеризується впливом учасників один на одного [3]. Завдання педагога полягає в тому, щоб у кожному конкретному випадку вибрати оптимальний варіант дидактичної взаємодії, тобто якнайкраще врахувати можливості самих студентів, сприяти прояву їх самостійності, передбачити раціональні форми управління їх навчальною діяльністю для досягнення максимально можливих результатів за мінімальну кількість часу, а студента засвоювати інформацію, навчальний матеріал від викладача. Суб'єкт-об'єктна модель навчання існувала довгий час, коли основним джерелом інформації виступав викладач. Світ не стоїть на місці, розширюються горизонти, з'являються нові технології навчання, будь-яка інформація стає доступною в будь-якому місці та будь-який час, студенти отримують доступ до великої кількості віртуальних об'єктів тощо. В результаті цього змінюється і сама схема педагогічної взаємодії. Базуючись на такій ¥ї характеристиці, як активність усіх учасників, схему трактують як двосторонню суб'єкт-суб' єктну взаємодію S1 S2, де $\mathrm{S} 1$ - викладач і S2 - студент утворюють загальний сукупний суб'єкт [4].

За такої моделі активну (домінуючу) роль займає студент, який в процесі навчання займається пошуком інформації та її свідомої інтерпретації, плануванням, організацією та проектуванням власної навчальної діяльності, має можливість впливати на процес навчання і нести відповідальність а його результат, за викладачем залишається роль - помічника, який підтримує пошук і інтерпретацію знань, забезпечує обмін інформацією між всіма учасниками освітнього процесута корекція помилок в процесі отримання знань.

Другою педагогічною умовою $є$ зміна мотивації в прочесі навчання шляхом інтеграції інформаційно-комунікаційних технологій в прочесі навчання педагогічних дисциплін.

Навчальна діяльність $є$ основною в процесі підготовки майбутніх інженерів - педагогів комп'ютерного профілю, адже в ході її здійснення студенти засвоюють знання, формують уміння в процесі чого розвивається той кого навчають. Провідним компонентом навчальної діяльності $є$ мотивація, бо від неї в значній мірі залежить результат навчання студентів.

Під поняттям “мотивація” в психологопедагогогічній літературі розуміють, процес в результаті якого діяльність набуває для людини особистісного сенсу, створює стійкий інтерес до неї і перетворює зовнішні задані цілі його діяльності в внутрішні потреби особистості [6].

Традиційно мотивацію поділяють на зовнішню та внутрішню (А.К. Маркова, Л.І. Божович та інші). При цьому доведено, що найбільший вплив на ефективність навчальної діяльності оказують внутрішні мотиви (мотиви самореалізації, мотиви покращення результатів своєї діяльності та інші). Вони змушують студентів більш концентруватися на навчанні й підвищують їх активність в навчальній діяльності.

Для виявлення мотивації майбутніх інженерівпедагогів в процесі вивчення педагогічних дисциплін нами було застосовано методику 


\section{ПЕДАГОГІЧНІ УМОВИ АКТИВІЗАЦІЇ НАВЧАЛЬНОЇ ДІЯЛЬНОСТІ МАЙБУТНІХ ІНЖЕНЕРІВ-ПЕДАГОГІВ КОМП'ЮТЕРНОГО ПРОФІЛЮ}

"Мотивація навчання студентів педагогічного вузу" (С.А. Пакуліна, М.В. Овчинников). Експеримент проводився в Українській інженернопедагогічній академії. Під час дослідження приймали участь студенти 4 курсу факультету “Комп'ютерних та інтегрованих технологій в виробництві та освіті” гр.ДКІ-ПОК13 та ДКІПОК14пр. у кількості 53 чоловіка.

За результатами проведення анкетування було встановлено, що при вступі у навчальний заклад у $66 \%$ студентів переважали зовнішні мотиви, а у 34\% внутрішні мотиви. Виявлено професійні мотиви вибору спеціальності у $57 \%$ студентів $\epsilon$ зовнішні мотиви у $43 \%$ студентів внутрішні. На даний момент реально діючи мотиви у $61 \%$ зовнішні у $39 \%$ студентів внутрішні.

Виходячи $з$ проблеми нашого дослідження, зазначимо, що для ефективності навчання майбутніх інженерів-педагогів комп'ютерного профілю та активізаціїіх навчальної діяльності буде трансформація зовнішніх мотивів студентів у внутрішні шляхом інтеграції інформаційнокомунікаційних технологій в навчальний процес.

Третьою педагогічною умовою є корекція навчальної діяльності в проиесі оперативного зворотного зв'язку.

Поняття “зворотній зв'язок” вперше було ведене засновником кібернетики Н. Вінером і спочатку воно трактувалось, як “управління машиною на основі дійсного виконання нею наказів, а не очікуваного їх виконання”. Іншими словами, під зворотнім зв'язком розуміють інформацію, що надходить від контролюючої машини, необхідна для іiі правильної роботи під контролем системи, що управляє. В подальшому в результаті швидкого росту наукового знання поняття зворотного зв'язку починає активно використовуватися в широкому спектрі наукового пошуку. Б. Стариченко, грунтуючись в своїх дослідах на роботи дослідників, зокрема Р. Абдєєва, В. Беспалько, А. Братко, Д. Дубровського, доводить необхідність зворотного зв'язку між викладачем та студентами. На думку I. Підласого зворотній зв'язок - це основа якісного управління, його розвитку й укріпленню кожен викладач повинен приділяти пріоритетне значення [8].

Безпосереднє відношення до проблеми, що розглядається, тобто до проблеми оперативного зв'язку, має один із законів навчання, який сформулював Е.Торндайк - закон збереження, згідно до якого, якщо під час певного часу зв'язок між ситуацією і відповіддю не відновлюється, інтенсивність такого зв'язку слабшає, при інших рівних умовах вірогідність виникнення зв'язаної 3 ситуацією відповіді зменшується. Все це говорить про те, що оперативний зворотний зв'язок зі студентами в навчальному процесі $є$ однією $з$ найголовніших ланок в системі навчання і його необхідно здійснювати регулярно, по можливості перманентно.

Отже кожна $з$ визначених педагогічних умов спрямована на активізацію навчальної діяльності майбутніх інженерів-педагогів комп’ютерного профілю. У той же час кожна взята окремо педагогічна умова не може повністю реалізувати активізацію навчальної діяльності, лише їх системна єдність дозволяє реалізувати поставлену задачу.

\section{ЛIТЕРАТУРА}

1.Бабанский Ю. К. Как оптимизировать процесс обучения / Ю. К. Бабанский. - М., 1977. $-256 \mathrm{c}$.

2.Бабанский Ю. К. Педагогика / Ю. К. Бабанский. - М., 1988. - 432 с.

3.Балан Е. Л. Дидактическое взаимодействие преподавателей и студентов как фактор оптимизации процесса обучения: дис. канд. пед. наук: 13.00.01 / Балан Е. Л. - Одесса, 1994. $173 \mathrm{c}$.

4.Зимняя И. А. Педагогическая психология / И. А. Зимняя. - М.: Логос, 1999. - 384 с. - (. Изд. второе, доп., испр. и перераб).

5. Ипполитова Н. Анализ понятия “педагогические условия": сущность, классификация / Н. Ипполитова, Н. Стерхова. // Сб. науч. трудов General and Professional Education. -Польша, 2012. - C. 8-14.

6. Немов Р. С. Психология / Р. С. Немов. - М. Владос, 2010. - 687 с. - (Книга 1).

7. Новий тлумачний словник української мови [авт.-уклад. В.Яременко].- К.: Аконіт, 2008. - 862c.

8. Подласый И. П. Педагогика / И. П. Подласый. - М.: Владос, 1999. - 256 с.

9. Философский энциклопедический словарь [сост. Л. Ильичев и др.]. - М.: Сов. Энциклопедия, 1983. - 840c.

\section{REFERENCES}

1. Babanskiy, Yu. K. (1977). Kak optimizirovat protsess obucheniya [How to optimize the learning process]. Moscow, 256 p. [in Russian].

2. Babanskiy, Yu. K. (1988). Pedagogika [Pedagogy].Moscow,432 p. [in Russian].

3. Balan, E. L. (1994) Didakticheskoe vzaimodeystvie prepodavateleyi studentov kak faktor optimizatsii protsessa obucheniya [Didactic interaction of teachers and students as a factor in optimizing the learning process]. Candidate's thesis. Odessa, $173 \mathrm{p}$. [in Ukrainian].

4. Zimnyaya, I. A. (1999). Pedagogicheskaya 
psihologiya [Pedagogical psychology]. Moscow, 384 p. [in Russian].

5. Ippolitova, N. \& Sterhova, N. (2012). Analiz ponyatiya "pedagogicheskie usloviya": suschnost, klassifikatsiya [Analysis of the concept of "pedagogical conditions": essence, classification]. Sb. nauch. Trudov. General and Professional Education. Polsha, pp. 8-14 p.[in Poland].

6. Nemov, R. S. (2010). Psihologiya Kniga 1 [Psychology]. Moscow, 687 p. [in Russian].
7. Yaremenko, V. (2008). Noviy tlumachniy slovnik ukrayinskoyi movi [New Explanatory Dictionary of the Ukrainian Language]. Kyiv, 862 p. [in Ukrainian].

8. Podlasyiy, I. P. (1999). Pedagogika [Pedagogy]. Moscow, 687 p. [in Russian].

9. Ilichev, L. (1983). et al. Filosofskiy entsiklopedicheskiy slovar [Philosophical Encyclopedic Dictionary]. Moscow, 840 p. [in Russian].

Стаття надійшла до редакції 15.03.2018

УДК 82.09: 821.161.2

DOI:

Ірина Кузьміна, викладач словесних дисииплін Луцьького педагогічного коледжу

\section{ЕКСПРЕСІЯ ТА ПСИХОЛОГІЗМ СОЦАЛЬНИХ НОВЕЛ ВАСИЛЯ СТЕФАНИКА}

У статті подано аналіз новелістичної творчості Василя Стефаника, розкрито ї̈ психологізм, експресіонізм, акцентовано, зокрема, на соціальному тлі новел із сільського життя. Вказано на майстерність зображення письменником важкої праці селян у II пол. XIX-на поч. XX ст. Акцентовано на тому, що експресіонізм В. Стефаника зростав на зображенні болючих, стражденних, навіть апокаліптично-катастрофічних ситуацій у межових обставинах буття, а жанр новели був найсприятливішим трунтом для вираження душевних трагедій його героїв.

Ключові слова: експресіонізм; новела; психологізм; сільське життя; важка прачя; Василь Стефаник; соиіальне тло.

Jim. 11.

Iryna Kuzmina, Lecturer of the Verbal Disciplines Lutsk Pedagogical College

\section{EXPRESSIONISM AND PSYCHOLOGISM OF SOCIAL NOVELS WRITTEN BY VASYLSTEFANYK}

The analysis of the novel created by Vasyl Stefanyk was presented, the psychologism and expressionism of his novels were uncovered, the social background of novels from rural life was focused on in the article. The artful description of the peasants' intensive work in the second part of XIX - in the beginning of XX century was pointed out. It was focused on the fact, that the expressionism of Vasyl Stefanyk had developed on the description of painful, even apocalyptically catastrophic situations according to life circumstances. The genre of novel was a good platform to express the psychological tragedies of Vasyl Stefanyks' heroes.

The material of generalizations was provided by short stories written by Stefanyk during 1897-1900. Thematically, it can be divided as follows:

1) stories about recruiting ("Vyvodyly z sela" [They were taken out of the village], "Stratyvsya" [Executed]);

2) stories about emigration and the rapid impoverishment of the masses ("Kaminniy khrest" [The Stone Cross], "Mamyn synok" [Mother's Son], "Osin" [Autumn], "Z mista iduchy" [Going From the City], "Son" [Dream] and others);

3) novels about family tragedies caused by social reasons ("Sama samisinka" [Alone], "Klenovi lystky" [Maple leaves], "Skin" [Skin], "Katrusya", "Novyna" [News] etc.);

4) stories about the transformation of peasants into proletarians - landless poor people - and about the first vivid manifestations of class struggle in the countryside under the new social conditions ("Synya knyzhechka" [Blue Book], "Paliy", "Sud" [Court], "Lyst" [Letter]).

So, the expressionism of Vasyl Stefanyk has developed on the description of painful, even apocalyptically catastrophic situations according to life circumstances. The genre of novel was a good platform to express psychological tragedies of Vasyl Stefanyks' heroes.

Keywords: expressionism; a novel; psychologism; a rural life; an intensive work; Vasyl Stefanyk; social background.

7 остановка проблеми. На межі XIX -

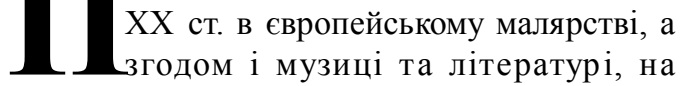
противагу імпресіонізмові, утверджується новий стиль - експресіонізм (або - як його ще іменували - неоімпресіонізм). 